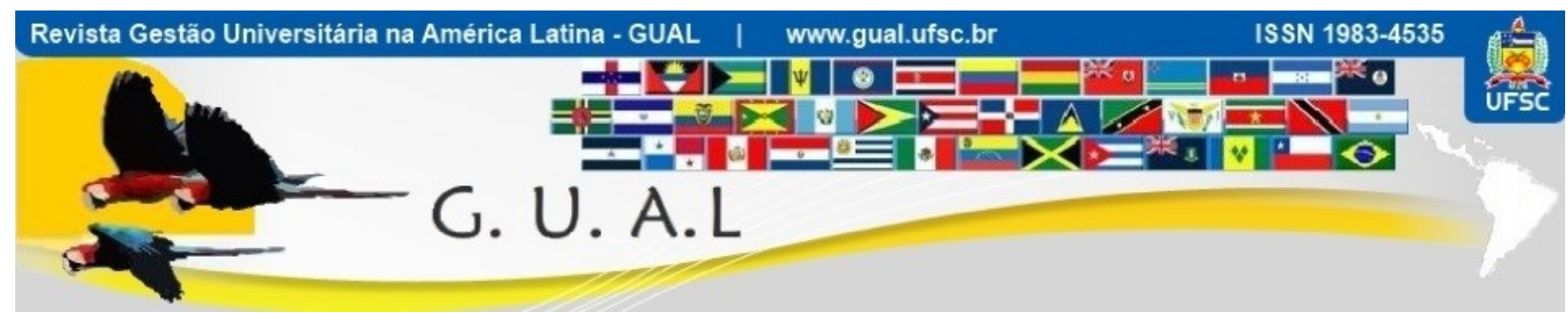

DOI: http://dx.doi.org/10.5007/1983-4535.2019v12n2p139

\title{
PANORAMA DOS PROGRAMAS DE PÓS-GRADUAÇÃO DA ÁREA DE PLANEJAMENTO URBANO E REGIONAL E DEMOGRAFIA: A LACUNA NAS REGIÕES NORTE, CENTRO-OESTE E NORDESTE
}

\author{
PANORAMA OF POSTGRADUATE PROGRAMS IN THE URBAN AND \\ REGIONAL PLANNING AND DEMOGRAPHY: THE GAP IN THE NORTH, \\ CENTRAL-WEST AND NORTHEAST REGIONS
}

\begin{abstract}
Rubens Staloch, Mestre https://orcid.org/0000-0001-9395-3422 rubens.staloch@udesc.br Universidade do Estado de Santa Catarina | Programa de Pós-Graduação em Planejamento Territorial e Desenvolvimento Socioambiental Florianópolis | Santa Catarina | Brasil

Isa de Oliveira Rocha, Doutora https://orcid.org/0000-0001-9840-0595 isa.rocha@udesc.br Universidade do Estado de Santa Catarina | Programa de Pós-Graduação em Planejamento Territorial e Desenvolvimento Socioambiental Florianópolis | Santa Catarina | Brasil
\end{abstract}

Recebido em 22/junho/2018

Aprovado em 28/dezembro/2018

Publicado em 02/maio/2019

Sistema de Avaliação: Double Blind Review

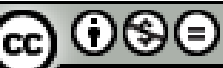

Esta obra está sob uma Licença Creative Commons Atribuição-Uso. 


\title{
RESUMO
}

Os Programas de Pós-Graduação no Brasil iniciaram sua trajetória nos anos de 1950, sendo que os primeiros Programas da área de Planejamento Urbano e Regional (PUR), assim denominados inicialmente, sem o campo da Demografia (D), surgem na década de 1970. Porém, por mais de uma década a contar de 1980, não ocorreu sua expansão territorial, verificada após os anos de 1990, sobretudo, nos anos 2000, inclusive, com a criação de Mestrados Profissionais. Atualmente, a área de avaliação na Capes é denominada Planejamento Urbano e Regional e Demografia (PLURD). Desta forma, ao buscar dados e informações, por meio de análise documental no Relatório de Avaliação da Área (2017), no website GeoCapes e na Plataforma Sucupira, objetivou-se realizar uma análise descritiva e quantitativa acerca dos Programas de Pós-Graduação da área PLURD no país. Como resultados, se pode destacar que há lacuna ou baixa oferta de Programas na área PLURD nas regiões Norte, Centro-Oeste e Nordeste; há igualmente baixa oferta de Programas Profissionais; e há ausência de Programas de Doutorado na região Centro-Oeste do país. Considerando a relevância da área, com destaque para a sua multi, inter e transdisciplinaridade, para o processo de desenvolvimento local e regional, se fazem necessários esforços para que todas as regiões do país possuam programas afins, que podem contribuir para o processo de reflexão teórica e prática aplicadas ao planejamento territorial [urbano e/ou regional].

Palavras-chave: Pós-Graduações. Planejamento Urbano e Regional e Demografia. Análise Histórica.

\begin{abstract}
Postgraduate Programs in Brazil started in the 1950s, with the first Programs in the Urban and Regional Planning (PUR) area, so called initially in 1970, without the area of Demography (D). However, for more than a decade after 1980, there was no territorial expansion, which occurred after the 1990s, especially in the years 2000, with the creation of the Professional Master's Degrees. Currently, the evaluation area in Capes is called Urban and Regional Planning and Demography (PLURD). In this way, by searching for data and information, through documentary analysis in the Relatório de Avaliação da Area (published in 2017), in the GeoCapes website and the Sucupira Platform, this text aims to perform a descriptive and quantitative analysis of the Posgraduate Programs at the PLURD area in the country. As a result, it can be highlighted that there is a gap or low supply of Programs in the PLURD area in the North, Midwest and Northeast regions; there is also a low supply of Professional Programs; and there is no $\mathrm{PhD}$ program in the Center-West region of the country. Considering the relevance of the area, emphasizing its multi, inter and transdisciplinarity, to the process of local and regional development, efforts will need to ensure that all regions of the country have related Programs that can contribute to the process of reflection theoretical, as well as for practices, above all, applied to territorial planning [urban and / or regional].
\end{abstract}

Keywords: Postgraduate. Urban and Regional Planning and Demography. Historical Analisys. 


\section{NOTAS INTRODUTÓRIAS}

Considerando o escopo das Pós-Graduações no país, estas tiveram início na década de 1950, impulsionadas especialmente com o processo de qualificação docente. Sobre a PósGraduação em Planejamento Urbano e Regional e Demografia (PLURD), avaliados pela Capes , no Brasil, em um período de 47 anos (1970 a 2017), o número passou de 6 para 46 Programas, o que demonstrou um crescimento significativo, em termos percentuais, de $667 \%$, ou ainda, uma taxa de crescimento geométrico de aproximadamente 7\% ao ano. Desta forma, se pode inferir que a expansão do número de Programas da Área foi mais rápida do que a expansão do conjunto da Pós-Graduação no país considerando que em 1998 havia 1.256 Programas e em 2016, 4.177 programas, conforme dados do portal GeoCapes .

De acordo com a Coordenação de Aperfeiçoamento de Pessoal de Nível Superior (CAPES), a Grande Área do Conhecimento denominada de Ciências Sociais Aplicadas é composta por outras 7 subáreas, dentre elas, Planejamento Urbano e Regional e Demografia (PLURD). Apesar do significativo aumento do número de Programas e da expansão territorial ocorrida no período recente, os Programas da Área PLURD estão concentrados nas regiões Sudeste e Sul do país, conforme se destaca ao longo do texto. Em dez Unidades da Federação ainda não existem cursos da Área PLURD, o que nos faz pensar na necessidade de ações que visem expandir a essas regiões também, principalmente no sentido de apoiar a criação de Programas nas regiões Nordeste, Norte e Centro-Oeste do país.

Pondera-se que um dos significativos desafios está na ampliação da cobertura territorial dos Programas PLURD e na qualificação dos mesmos, visto a relevância da área para o processo positivo de desenvolvimento do país. Assim sendo, o presente trabalho tem como foco perfazer uma análise quantitativa e descritiva no que diz respeito aos dados disponibilizados no portal GeoCapes, na Plataforma Sucupira e no Relatório de Avaliação 2017 (decorrente da avaliação do quadriênio 2013 - 2016) da área PLURD.

Posto isto, o texto a seguir está dividido em quatro seções: i) A Pós-Graduação na área de Planejamento Urbano e Regional e Demografia no Brasil: breves notas; ii) Metodologia utilizada; iii) Dados e análise de dados: onde estão [ou não estão] os Programas de PósGraduação em Planejamento Urbano e Regional e Demografia (PLURD) no Brasil; iv) Notas finais. 


\section{A PÓS-GRADUAÇÃO NA ÁREA DE PLANEJAMENTO URBANO E REGIONAL E DEMOGRAFIA NO BRASIL: BREVES NOTAS}

De forma geral, a Pós-Graduação no Brasil começa a tomar forma na década de 1960, e principalmente na década seguinte, quando houve uma maior orientação do governo brasileiro ao estímulo à Pós-Graduação, sobretudo, para professores do ensino superior, visando contribuir "para a expansão do próprio sistema e para a promoção da pesquisa científica e tecnológica no País" (PIQUET; VILANI, 2013, p. 96). De acordo com dados do Centro de Gestão de Estudos Estratégicos - CGEE - (2012, p. 39), no ano de 1965, quando foi regulamentada a Pós-Graduação no Brasil, havia apenas 27 Mestrados, em 1975 já eram 429 e em 1996 1.187. Os Programas de Doutorado somavam 11 em 1965, 149 em 1975 e em 1998 totalizavam 782 .

Atualmente, considerando dados da Plataforma Sucupira acessada em maio/2018, existem 4.341 Programas de Pós-Graduação [entre Mestrados Acadêmicos (ME), Doutorados (DO) e Mestrados Profissionais (MP)] $]^{1}$. Os 46 Programas da área PLURD representam hoje 1\% do total de Programas avaliados e qualificados pela Capes. (Quadro 1)

Quadro 1 Programas e Cursos de Pós-Graduação - Brasil e Área PLURD (2016).

\begin{tabular}{|c|c|c|c|c|c|c|c|c|c|}
\hline \multirow{2}{*}{ REGIÃO } & \multicolumn{5}{|c|}{ Total de Programas de Pós-Graduação } & \multicolumn{4}{|c|}{ Totais de Cursos de Pós-Graduação } \\
\hline & Total & ME & DO & MP & ME/DO & Total & ME & DO & MP \\
\hline Centro-Oeste & 355 & 144 & 11 & 51 & 149 & 504 & 293 & 160 & 51 \\
\hline Nordeste & 879 & 390 & 16 & 146 & 327 & 1206 & 717 & 343 & 146 \\
\hline Norte & 239 & 112 & 3 & 47 & 77 & 318 & 189 & 81 & 48 \\
\hline Sudeste & 1933 & 417 & 41 & 374 & 1101 & 3034 & 1518 & 1142 & 374 \\
\hline Sul & 935 & 311 & 11 & 152 & 461 & 1396 & 772 & 472 & 152 \\
\hline Totais & 4341 & 1374 & 82 & 770 & 2115 & 6458 & 3489 & 2198 & 771 \\
\hline \multirow{2}{*}{$\begin{array}{l}\text { PLURD } \\
\text { (2017) }\end{array}$} & \multicolumn{5}{|c|}{ Total de Programas de Pós-Graduação em PLURD } & \multicolumn{4}{|c|}{$\begin{array}{c}\text { Total de Cursos de Pós-Graduação en } \\
\text { PLURD } \\
\end{array}$} \\
\hline & 46 & 20 & 2 & 8 & 16 & 62 & 36 & 18 & 8 \\
\hline$\%$ do Total & $1 \%$ & $1 \%$ & $2 \%$ & $1 \%$ & $1 \%$ & $1 \%$ & $1 \%$ & $1 \%$ & $1 \%$ \\
\hline
\end{tabular}

Mestrado Acadêmico (ME); Doutorado (DO); Mestrado Profissional (MP); Mestrado e Doutorado (ME/DO)

Fonte: elaborado pelos autores a partir dos dados coletados no Relatório de Avaliação 2017 da Capes e da Plataforma Sucupira (acessado em maio de 2018).

\footnotetext{
${ }^{1}$ Importante destacar que em 1976 a Capes normatizou o Sistema de Avaliação da Pós-Graduação no Brasil, que por sua vez, está ativo até hoje para diferentes áreas de avaliação. Os critérios de avaliação versam sobre o estabelecimento de padrões de qualidade dos cursos, o estímulo ao impulso da evolução do Sistema Nacional de Pós-Graduação, bem como, de cada Programa, em particular e ainda, visa contribuir com o aumento da eficiência dos Programas para atendes as necessidades nacionais, regionais e urbanas (PORTO; THEIS, 2016). Os Programas de Pós-Graduação stricto sensu são avaliados anualmente pela Capes, uma tarefa complexa e que envolve diversos critérios/quesitos: 1) Proposta do Programa; 2) Corpo Docente; 3) Corpo Discente; 4) Produção Intelectual; 5) Inserção Social.
} 


\section{PANORAMA DOS PROGRAMAS DE PÓS-GRADUAÇÃO DA ÁREA DE PLANEJAMENTO URBANO E REGIONAL E DEMOGRAFIA: A LACUNA NAS REGIÕES NORTE, CENTRO-OESTE E NORDESTE DOI: http://dx.doi.org/10.5007/1983-4535.2019v12n2p139}

No âmbito das regiões brasileiras, as Pós-Graduações destacam-se, de acordo com o maior número ofertado, nas regiões Sudeste, Sul e Nordeste, respectivamente. Assim como se percebe ao longo dos tempos [porém, não de forma constante e homogênea] o aumento do número de Programas de Pós-Graduação e Cursos, também se verifica um número crescente de matrículas, especialmente em nível de ME e DO. (Gráfico 1).

Gráfico 1 matrículas Stricto Sensu por tipo de curso (1999-2016) de todas as áreas no Brasil.

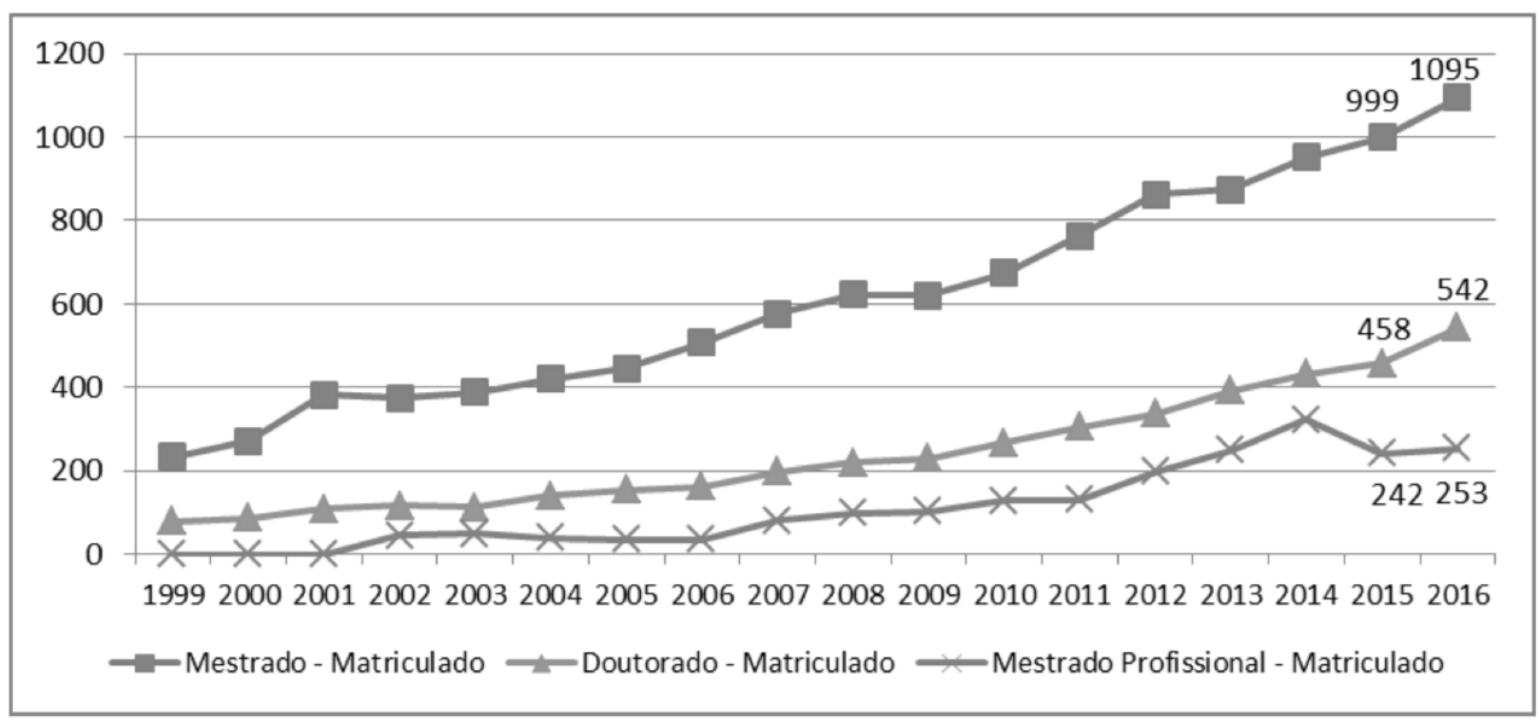

Fonte: extraído e adaptado do Relatório de Avaliação 2017.

A área de avaliação em Planejamento Urbano e Regional e Demografia (PLURD) está composta por duas subáreas: uma de Planejamento Urbano e Regional [PUR] e a outra de Demografia [D]. A primeira subárea originou-se da criação, no início da década de 1970, dos primeiros cursos de mestrado com a finalidade de formar quadros qualificados tanto para a formulação como para a implementação de políticas urbanas e regionais [estipuladas e idealizadas pelo governo militar vigente].

No âmbito da área de avaliação da Capes em Planejamento Urbano e Regional, o primeiro curso de mestrado em Planejamento Regional e Urbano no Brasil teve seu início na década de 1970, na região Sul, na Universidade Federal do Rio Grande do Sul (UFRGS / $1970^{2}$ ). Na região Sudeste iniciou com a Universidade Federal do Rio de Janeiro (UFRJ / 1972) e no Nordeste com a Universidade Federal de Pernambuco (UFPE / 1975) (PIQUET; VILANI, 2013). Desta forma, Porto; Theis (2016) descrevem o período de 1970 a 1999 como

\footnotetext{
2 A mesma instituicão, já em 1965, havia criado o Centro de Desenvolvimento e Planejamento Regional (Cedeplar), cuja finalidade estava já direcionada a abrigar um Programa de pesquisa e ensino de Pós-Graduação na área de Economia Regional (PIQUET; VILANI, 2013).
} 
a "gênese" dos Programas de Planejamento Urbano e Regional. Ainda, Limonad (2017, p. 221) recorda que:

[...] esses programas de planejamento urbano e regional se constituíram, entre 1971- 1972, no âmbito de um convênio, com duração prevista de sete anos, realizado entre a Coordenação de Aperfeiçoamento de Pessoal de Ensino Superior (CAPES), órgão do Ministério da Educação, e o Ministério do Interior com suporte e financiamento direto desse ministério. Convênio esse realizado em decorrência de uma intenção expressa de formar quadros para órgãos de governo, com base nas metas do II Plano Nacional de Desenvolvimento, elaborado durante o governo do presidente general Emilio Garrastazu Médici (1969-1973), um dos mais duros governos da ditadura militar.

Durante a década de 1980 pouco, ou nada, se fez em termos de criação de Programas na área de Planejamento Urbano e Regional, "sendo sintomático que no período de quase 20 anos (entre 1975 e 1993) nenhum novo curso tenha sido proposto na área" (PIQUET; VILANI, 2013, p. 100). A partir dos anos de 1990, sobretudo, após os anos 2000, com as novas políticas econômicas, sociais etc. do país, os programas na área PLURD iniciaram uma crescente no número de cursos ofertados. Neste sentido, o presente trabalho se prontifica a realizar análise acerca dos programas na área PLURD, perfazendo, quando necessário, atualizações àqueles trabalhos já publicados, a exemplo do texto de Porto; Theis, (2016), e ainda, se realiza uma correlação dos dados encontrados com algumas reflexões dos autores.

\section{METODOLOGIA UTILIZADA}

Ao buscar entender o panorama acerca dos Programas em Planejamento Urbano e Regional e Demografia, o presente trabalho se pautou em uma análise documental no Relatório de Avaliação 2017 da área CAPES em Planejamento Urbano e Regional e Demografia (PLURD), em dados do website GeoCapes e da Plataforma Sucupira. Desta forma, se trata de uma análise descritiva e quantitativa acerca dos Programas da referida área. Para a tabulação dos dados coletados foram utilizados o Software Microsoft Excel e o auxílio do Adobe Photoshop para a realização da representação visual da distribuição geográfica dos Programas nas regiões brasileiras. 


\section{DADOS E ANÁLISE DE DADOS: ONDE SÃO ENCONTRADOS [E A FALDA DOS] OS PROGRAMAS DE PÓS-GRADUAÇÃO EM PLANEJAMENTO URBANO E REGIONAL E DEMOGRAFIA (PLURD) NO BRASIL?}

Como já mencionado, a partir dos anos de 1990, sobretudo, após os anos 2000, com as novas políticas econômicas, sociais etc. do país, os Programas na área PLURD expandem-se inclusive, já citado anteriormente, se inicia a fase de criação dos Mestrados Profissionais (MP). Considera-se estes, o primeiro deles surgiu em 2001 na Universidade Cândido Mendes (UCAM), em Campos dos Goytacazes (RJ), na região Sudeste; sendo esta precursora na área pela criação de um Doutorado (acadêmico) a partir de um MP. As instituições de status jurídico privado, se pode assim dizer, foram,-as grandes responsáveis pelas instalações dos MP no país dos quais, ainda hoje, dos oito Mestrados Profissionais da área PLURD, cinco são ofertados por instituições privadas, conforme se verifica no Quadro 2.

Destaca-se que na primeira década do século XX houve um aumento no crescimento de programas da área, especialmente na subárea de Planejamento Urbano e Regional. De 2010 até 2017 foram credenciados trinta programas, entre os quais cinco MP. Por ora, mesmo com a aprovação/autorização para criação de doutorados profissionais ${ }^{3}$ no país, na área de avaliação PLURD até dezembro/2017 não havia proposta aprovada nesta modalidade. É inegável que há uma evolução na quantidade de programas da área em questão ao longo dos anos, porém, não de forma homogênea e constante. (Gráfico 2)

Gráfico 2 Programas área PLURD, por grau (1970-2017).

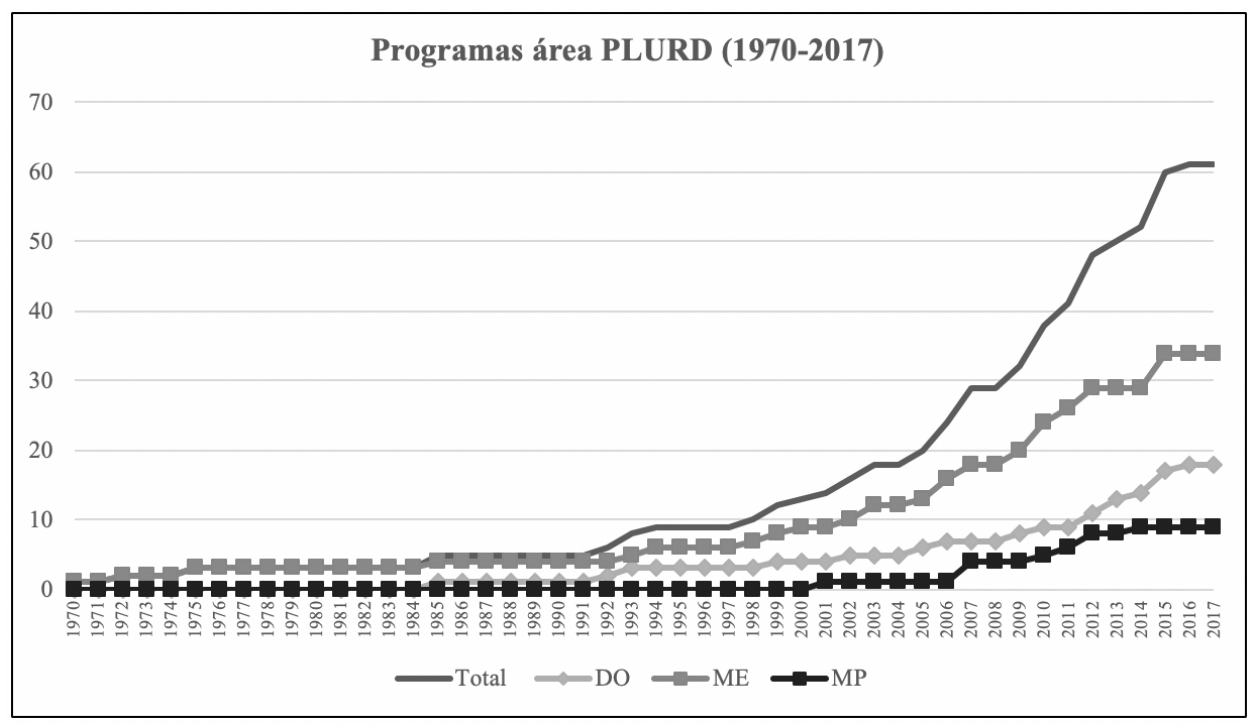

Fonte: elaborado a partir dos dados coletados no Relatório de Avaliação 2017 e da Plataforma Sucupira (acessado em maio de 2018).

\footnotetext{
${ }^{3}$ Instituído pela Portaria n ${ }^{\circ} 389$, de 23 de março de 2017 do Ministério da Educação (MEC).
} 


\section{PANORAMA DOS PROGRAMAS DE PÓS-GRADUAÇÃO DA ÁREA DE PLANEJAMENTO URBANO E REGIONAL E DEMOGRAFIA: A LACUNA NAS REGIÕES NORTE, CENTRO-OESTE E NORDESTE DOI: http://dx.doi.org/10.5007/1983-4535.2019v12n2p139}

Perfazendo uma descrição geral acerca da característica destes Programas, assim como evidenciaram Ranfolph $(2013)^{4}$ e Porto; Theis $(2016)^{5}$, a maior parte deles estão sendo ofertados nas regiões Sudeste e Sul (63\% do total): (Quadro 2)

Quadro 2 Programas de Pós-Graduação da Área PLURD (2016).

\begin{tabular}{|c|c|c|c|c|c|c|c|c|}
\hline & UF & Município & $\begin{array}{c}\text { Sigla da } \\
\text { Instituicão }\end{array}$ & Status Jurídico & Nome do Programa & Criação & Grau & Nota \\
\hline \multirow{3}{*}{ 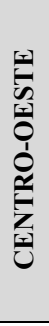 } & GO & GOIÂNIA & ALFA & PARTICULAR & $\begin{array}{c}\text { DESENVOLVIMENTO } \\
\text { REGIONAL }\end{array}$ & 2007 & $\begin{array}{l}\text { Mestrado } \\
\text { Profissional } \\
\text { [PUR] }\end{array}$ & 3 \\
\hline & GO & GOIÂNIA & PUC-GOIÁS & PARTICULAR & $\begin{array}{c}\text { DESENVOLVIMENTO } \\
\text { E PLANEJAMENTO } \\
\text { TERRITORIAL }\end{array}$ & 2006 & $\begin{array}{l}\text { Mestrado } \\
\text { [PUR] }\end{array}$ & 3 \\
\hline & MS & PONTA PORÃ & UEMS & ESTADUAL & $\begin{array}{c}\text { DESENVOLVIMENTO } \\
\text { REGIONAL E DE } \\
\text { SISTEMAS } \\
\text { PRODUTIVOS }\end{array}$ & 2014 & $\begin{array}{l}\text { Mestrado } \\
\text { [PUR] }\end{array}$ & 3 \\
\hline \multirow{5}{*}{ 䆥 } & AP & MACAPÁ & UNIFAP & FEDERAL & $\begin{array}{c}\text { MESTRADO } \\
\text { INTEGRADO EM } \\
\text { DESENVOLVIMENTO } \\
\text { REGIONAL }\end{array}$ & 2006 & $\begin{array}{l}\text { Mestrado } \\
\text { [PUR] }\end{array}$ & 3 \\
\hline & PA & BELÉM & UNAMA & PARTICULAR & $\begin{array}{c}\text { DESENVOLVIMENTO } \\
\text { E MEIO AMBIENTE } \\
\text { URBANO }\end{array}$ & 2007 & $\begin{array}{l}\text { Mestrado } \\
\text { [PUR] }\end{array}$ & 4 \\
\hline & $\mathrm{RR}$ & BOA VISTA & UFRR & FEDERAL & $\begin{array}{c}\text { DESENVOLVIMENTO } \\
\text { REGIONAL DA } \\
\text { AMAZÔNIA }\end{array}$ & 2012 & $\begin{array}{l}\text { Mestrado } \\
\text { [PUR] }\end{array}$ & 3 \\
\hline & TO & PALMAS & UFT & FEDERAL & $\begin{array}{l}\text { DESENVOLVIMENTO } \\
\text { REGIONAL }\end{array}$ & $\begin{array}{l}2007 / \\
2015\end{array}$ & $\begin{array}{l}\text { Mestrado/ } \\
\text { Doutorado } \\
\text { [PUR] }\end{array}$ & 4 \\
\hline & TO & PALMAS & UFT & FEDERAL & $\begin{array}{c}\text { GESTÃO DE } \\
\text { POLÍTICAS PÚBLICAS }\end{array}$ & 2012 & $\begin{array}{l}\text { Mestrado } \\
\text { Profissional } \\
\text { [PUR] }\end{array}$ & 3 \\
\hline \multirow{9}{*}{ 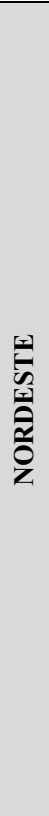 } & BA & SALVADOR & UCSAL & PARTICULAR & $\begin{array}{c}\text { PLANEJAMENTO } \\
\text { TERRITORIAL E } \\
\text { DESENVOLVIMENTO } \\
\text { SOCIAL }\end{array}$ & $\begin{array}{l}2005 / \\
2012\end{array}$ & $\begin{array}{c}\text { Mestrado/ } \\
\text { Doutorado } \\
\text { [PUR] }\end{array}$ & 4 \\
\hline & BA & SALVADOR & UCSAL & PARTICULAR & $\begin{array}{c}\text { PLANEJAMENTO } \\
\text { AMBIENTAL } \\
\end{array}$ & 2007 & $\begin{array}{l}\text { Mestrado } \\
\text { Profissional }\end{array}$ & 3 \\
\hline & BA & SALVADOR & UNIFACS & PARTICULAR & $\begin{array}{l}\text { DESENVOLVIMENTO } \\
\text { REGIONAL E URBANO }\end{array}$ & $\begin{array}{l}1999 / \\
2006\end{array}$ & $\begin{array}{l}\text { Mestrado/ } \\
\text { Doutorado } \\
\text { [PUR] }\end{array}$ & $3 / 2^{6}$ \\
\hline & MA & SÃO LUÍS & UEMA & ESTADUAL & $\begin{array}{l}\text { DESENVOLVIMENTO } \\
\text { SOCIOESPACIAL E } \\
\text { REGIONAL }\end{array}$ & 2010 & $\begin{array}{l}\text { Mestrado } \\
\text { [PUR] }\end{array}$ & 3 \\
\hline & PB & $\begin{array}{l}\text { CAMPINA } \\
\text { GRANDE }\end{array}$ & UEPB & ESTADUAL & $\begin{array}{c}\text { DESENVOLVIMENTO } \\
\text { REGIONAL } \\
\end{array}$ & 2009 & $\begin{array}{c}\text { Mestrado } \\
\text { [PUR] }\end{array}$ & 3 \\
\hline & PE & RECIFE & UFPE & FEDERAL & $\begin{array}{c}\text { DESENVOLVIMENTO } \\
\text { URBANO }\end{array}$ & $\begin{array}{l}1975 / \\
1999\end{array}$ & $\begin{array}{l}\text { Mestrado/ } \\
\text { Doutorado } \\
\text { [PUR] }\end{array}$ & 5 \\
\hline & $\mathrm{RN}$ & NATAL & UFRN & FEDERAL & $\begin{array}{c}\text { ESTUDOS URBANOS E } \\
\text { REGIONAIS }\end{array}$ & 2009 & $\begin{array}{l}\text { Mestrado } \\
\text { [PUR] }\end{array}$ & 4 \\
\hline & $\mathrm{RN}$ & NATAL & UFRN & FEDERAL & DEMOGRAFIA & 2011 & $\begin{array}{l}\text { Mestrado } \\
{[\mathrm{D}]}\end{array}$ & 4 \\
\hline & $\mathrm{RN}$ & PAU DOS FERROS & UERN & ESTADUAL & $\begin{array}{l}\text { PLANEJAMENTO E } \\
\text { DINÂMICAS } \\
\text { TERRITORIAIS NO } \\
\text { SEMIÁRIDO }\end{array}$ & 2015 & $\begin{array}{l}\text { Mestrado } \\
\text { [PUR] }\end{array}$ & 3 \\
\hline
\end{tabular}

\footnotetext{
${ }^{4} \mathrm{O}$ autor, em seu estudo, apresentou trinta e dois Programas, sendo estes, aqueles criados e instalados até a data da publicação do texto. Sendo assim, o presente trabalho atualizou os referidos dados até a data de 2016, com a publicação do quadriênio 2017 (2013-2016) da Capes e consulta na base de dados da Plataforma Sucupira.

${ }^{5}$ Complementando e atualizando, neste trabalho, os dados por eles apresentados.

${ }^{6}$ Capes recomenda descredenciamento do doutorado.
} 
PANORAMA DOS PROGRAMAS DE PÓS-GRADUAÇÃO DA ÁREA DE PLANEJAMENTO URBANO E REGIONAL E DEMOGRAFIA: A LACUNA NAS REGIÕES NORTE, CENTRO-OESTE E NORDESTE DOI: http://dx.doi.org/10.5007/1983-4535.2019v12n2p139

\begin{tabular}{|c|c|c|c|c|c|c|c|c|}
\hline & $\mathbf{U F}$ & Município & $\begin{array}{c}\text { Sigla da } \\
\text { Instituicão }\end{array}$ & Status Jurídico & Nome do Programa & Criação & Grau & Nota \\
\hline \multirow{15}{*}{ 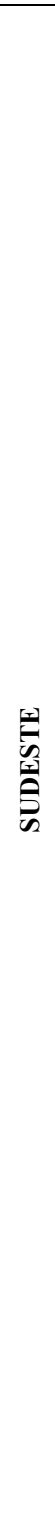 } & MG & DIVINÓPOLIS & INESP & PARTICULAR & $\begin{array}{c}\text { DESENVOLVIMENTO } \\
\text { REGIONAL }\end{array}$ & 2012 & $\begin{array}{l}\text { Mestrado } \\
\text { Profissional } \\
\text { [PUR] }\end{array}$ & $2^{7}$ \\
\hline & MG & $\begin{array}{c}\text { BELO } \\
\text { HORIZONTE }\end{array}$ & UFMG & FEDERAL & DEMOGRAFIA & $\begin{array}{l}1985 / \\
1985\end{array}$ & $\begin{array}{c}\text { Mestrado/ } \\
\text { Doutorado } \\
{[\mathrm{D}]} \\
\end{array}$ & 7 \\
\hline & MG & $\begin{array}{c}\text { BELO } \\
\text { HORIZONTE }\end{array}$ & UFMG & FEDERAL & $\begin{array}{l}\text { SOCIEDADE, } \\
\text { AMBIENTE E } \\
\text { TERRITÓRIO }\end{array}$ & 2015 & $\begin{array}{l}\text { Mestrado } \\
\text { [PUR] }\end{array}$ & 3 \\
\hline & MG & PASSOS & FESP & PARTICULAR & $\begin{array}{c}\text { DESENVOLVIMENTO } \\
\text { REGIONAL E MEIO } \\
\text { AMBIENTE }\end{array}$ & 2014 & $\begin{array}{l}\text { Mestrado } \\
\text { Profissional } \\
\text { [PUR] }\end{array}$ & 3 \\
\hline & $\mathrm{RJ}$ & $\begin{array}{l}\text { CAMPOS DOS } \\
\text { GOYTACAZES }\end{array}$ & UCAM & PARTICULAR & $\begin{array}{c}\text { PLANEJAMENTO } \\
\text { REGIONAL E GESTÃO } \\
\text { DA CIDADE } \\
\end{array}$ & 2001 & $\begin{array}{l}\text { Mestrado } \\
\text { Profissional } \\
\text { [PUR] }\end{array}$ & 4 \\
\hline & RJ & $\begin{array}{l}\text { CAMPOS DOS } \\
\text { GOYTACAZES }\end{array}$ & UFF & FEDERAL & $\begin{array}{c}\text { DESENVOLVIMENTO } \\
\text { REGIONAL, } \\
\text { AMBIENTE E } \\
\text { POLÍTICAS PÚBLICAS }\end{array}$ & 2015 & $\begin{array}{l}\text { Mestrado } \\
\text { [PUR] }\end{array}$ & 3 \\
\hline & RJ & RIO DE JANEIRO & ENCE & FEDERAL & $\begin{array}{c}\text { POPULAÇÃO, } \\
\text { TERRITÓRIO E } \\
\text { ESTATÍSTICAS } \\
\text { PÚBLICAS }\end{array}$ & $\begin{array}{l}1998 / \\
2013\end{array}$ & $\begin{array}{l}\text { Mestrado/ } \\
\text { Doutorado } \\
\text { [D] }\end{array}$ & 4 \\
\hline & RJ & RIO DE JANEIRO & UCAM & PARTICULAR & $\begin{array}{c}\text { PLANEJAMENTO } \\
\text { REGIONAL E GESTÃO } \\
\text { DA CIDADE }\end{array}$ & 2015 & $\begin{array}{l}\text { Doutorado } \\
\text { [PUR] }\end{array}$ & 4 \\
\hline & RJ & RIO DE JANEIRO & UFRJ & FEDERAL & $\begin{array}{c}\text { PLANEJAMENTO } \\
\text { URBANO E REGIONAL }\end{array}$ & $\begin{array}{l}1972 / \\
1993\end{array}$ & $\begin{array}{c}\text { Mestrado/ } \\
\text { Doutorado } \\
\text { [PUR] }\end{array}$ & 6 \\
\hline & RJ & SEROPÉDICA & UFRRJ & FEDERAL & $\begin{array}{l}\text { DESENVOLVIMENTO } \\
\text { TERRITORIAL E } \\
\text { POLÍTICAS PÚBLICAS } \\
\end{array}$ & 2012 & $\begin{array}{c}\text { Mestrado } \\
\text { [PUR] }\end{array}$ & 3 \\
\hline & SP & CAMPINAS & UNICAMP & ESTADUAL & DEMOGRAFIA & $\begin{array}{l}2002 / \\
1992\end{array}$ & $\begin{array}{c}\text { Mestrado/ } \\
\text { Doutorado } \\
{[\mathrm{D}]}\end{array}$ & 6 \\
\hline & SP & $\begin{array}{l}\text { SÃO BERNARDO } \\
\text { DO CAMPO }\end{array}$ & UFABC & FEDERAL & $\begin{array}{l}\text { PLANEJAMENTO E } \\
\text { GESTÃO DO } \\
\text { TERRITÓRIO } \\
\end{array}$ & $\begin{array}{l}2011 / \\
2013\end{array}$ & $\begin{array}{l}\text { Mestrado/ } \\
\text { Doutorado } \\
\text { [PUR] }\end{array}$ & 4 \\
\hline & SP & $\begin{array}{l}\text { SÃO JOSÉ DOS } \\
\text { CAMPOS }\end{array}$ & UNIVAP & PARTICULAR & $\begin{array}{c}\text { PLANEJAMENTO } \\
\text { URBANO E REGIONAL }\end{array}$ & $\begin{array}{l}1993 / \\
2014\end{array}$ & $\begin{array}{l}\text { Mestrado/ } \\
\text { Doutorado } \\
\text { [PUR] }\end{array}$ & 4 \\
\hline & SP & SÃO PAULO & UNINOVE & PARTICULAR & $\begin{array}{c}\text { CIDADES } \\
\text { INTELIGENTES E } \\
\text { SUSTENTÁVEIS } \\
\end{array}$ & 2015 & $\begin{array}{l}\text { Mestrado } \\
\text { [PUR] }\end{array}$ & 3 \\
\hline & SP & TAUBATÉ & UNITAU & MUNICIPAL & $\begin{array}{c}\text { PLANEJAMENTO E } \\
\text { DESENVOLVIMENTO } \\
\text { REGIONAL }\end{array}$ & 2010 & $\begin{array}{l}\text { Mestrado } \\
\text { [PUR] }\end{array}$ & 3 \\
\hline \multirow{7}{*}{ Son } & PR & CURITIBA & PUC/PR & PARTICULAR & GESTÃO URBANA & $\begin{array}{l}2003 / \\
2009\end{array}$ & $\begin{array}{c}\text { Mestrado/ } \\
\text { Doutorado } \\
\text { [PUR] }\end{array}$ & 5 \\
\hline & PR & CURITIBA & UFPR & FEDERAL & $\begin{array}{c}\text { PLANEJAMENTO } \\
\text { URBANO }\end{array}$ & 2015 & $\begin{array}{c}\text { Mestrado } \\
\text { [PUR] }\end{array}$ & 3 \\
\hline & PR & CURITIBA & UTFPR & FEDERAL & $\begin{array}{c}\text { PLANEJAMENTO E } \\
\text { GOVERNANÇA } \\
\text { PÚBLICA }\end{array}$ & 2011 & $\begin{array}{l}\text { Mestrado } \\
\text { Profissional } \\
\text { [PUR] }\end{array}$ & 3 \\
\hline & PR & FOZ DO IGUAÇU & UNILA & FEDERAL & $\begin{array}{l}\text { POLÍTICAS PÚBLICAS } \\
\text { E } \\
\text { DESENVOLVIMENTO }\end{array}$ & 2015 & $\begin{array}{l}\text { Mestrado } \\
\text { [PUR] }\end{array}$ & 3 \\
\hline & PR & PATO BRANCO & UTFPR & FEDERAL & $\begin{array}{c}\text { DESENVOLVIMENTO } \\
\text { REGIONAL }\end{array}$ & 2010 & $\begin{array}{c}\text { Mestrado } \\
\text { [PUR] }\end{array}$ & 3 \\
\hline & PR & TOLEDO & UNIOESTE & ESTADUAL & $\begin{array}{c}\text { DESENVOLVIMENTO } \\
\text { REGIONAL E } \\
\text { AGRONEGÓCIO }\end{array}$ & $\begin{array}{l}2003 / \\
2010\end{array}$ & $\begin{array}{c}\text { Mestrado/ } \\
\text { Doutorado } \\
\text { [PUR] }\end{array}$ & 5 \\
\hline & RS & IJUÍ & UNIJUÍ & PARTICULAR & $\begin{array}{c}\text { DESENVOLVIMENTO } \\
\text { REGIONAL } \\
\end{array}$ & $\begin{array}{l}2012 / \\
2015 \\
\end{array}$ & $\begin{array}{l}\text { Mestrado/ } \\
\text { Doutorado }\end{array}$ & 4 \\
\hline
\end{tabular}

${ }^{7}$ De acordo com Plataforma Sucupira, está em desativação. Desta forma, não fará parte das avaliações posteriores deste trabalho (Acessado em maio de 2018). 
PANORAMA DOS PROGRAMAS DE PÓS-GRADUAÇÃO DA ÁREA DE PLANEJAMENTO URBANO E REGIONAL E DEMOGRAFIA: A LACUNA NAS REGIÕES NORTE, CENTRO-OESTE E NORDESTE DOI: http://dx.doi.org/10.5007/1983-4535.2019v12n2p139

\begin{tabular}{|c|c|c|c|c|c|c|c|}
\hline UF & Município & $\begin{array}{c}\text { Sigla da } \\
\text { Instituicão }\end{array}$ & Status Jurídico & Nome do Programa & Criação & Grau & Nota \\
\hline & & & & & & [PUR] & \\
\hline RS & PORTO ALEGRE & UFRGS & FEDERAL & $\begin{array}{l}\text { PLANEJAMENTO } \\
\text { URBANO E REGIONAL }\end{array}$ & $\begin{array}{l}1970 / \\
2004\end{array}$ & $\begin{array}{l}\text { Mestrado/ } \\
\text { Doutorado } \\
\text { [PUR] }\end{array}$ & 6 \\
\hline RS & $\begin{array}{c}\text { SANTA CRUZ DO } \\
\text { SUL }\end{array}$ & UNISC & PARTICULAR & $\begin{array}{l}\text { DESENVOLVIMENTO } \\
\text { REGIONAL }\end{array}$ & $\begin{array}{l}1994 / \\
2005\end{array}$ & $\begin{array}{l}\text { Mestrado/ } \\
\text { Doutorado } \\
\text { [PUR] }\end{array}$ & 5 \\
\hline RS & TAQUARA & FACCAT-RS & PARTICULAR & $\begin{array}{c}\text { DESENVOLVIMENTO } \\
\text { REGIONAL }\end{array}$ & 2012 & $\begin{array}{l}\text { Mestrado } \\
\text { [PUR] }\end{array}$ & 3 \\
\hline $\mathrm{SC}$ & BLUMENAU & FURB & MUNICIPAL & $\begin{array}{l}\text { DESENVOLVIMENTO } \\
\text { REGIONAL }\end{array}$ & $\begin{array}{l}2000 / \\
2012\end{array}$ & $\begin{array}{l}\text { Mestrado/ } \\
\text { Doutorado } \\
\text { [PUR] }\end{array}$ & 5 \\
\hline $\mathrm{SC}$ & CANOINHAS & UNC & MUNICIPAL & $\begin{array}{l}\text { DESENVOLVIMENTO } \\
\text { REGIONAL }\end{array}$ & 2006 & $\begin{array}{l}\text { Mestrado } \\
\text { [PUR] }\end{array}$ & 3 \\
\hline $\mathrm{SC}$ & CHAPECÓ & UNOCHAPECÓ ${ }^{8}$ & PARTICULAR & $\begin{array}{c}\text { POLÍTICAS SOCIAIS E } \\
\text { DINÂMICAS } \\
\text { REGIONAIS } \\
\end{array}$ & 2010 & $\begin{array}{l}\text { Mestrado } \\
\text { Profissional } \\
\text { [PUR] }\end{array}$ & 3 \\
\hline $\mathrm{SC}$ & FLORIANÓPOLIS & UDESC & ESTADUAL & $\begin{array}{c}\text { PLANEJAMENTO } \\
\text { TERRITORIAL E } \\
\text { DESENVOLVIMENTO } \\
\text { SÓCIO-AMBIENTAL }\end{array}$ & 2007 & $\begin{array}{l}\text { Mestrado } \\
\text { Profissional } \\
\text { [PUR] }\end{array}$ & 4 \\
\hline $\mathrm{SC}$ & FLORIANÓPOLIS & UDESC & ESTADUAL & $\begin{array}{c}\text { PLANEJAMENTO } \\
\text { TERRITORIAL E } \\
\text { DESENVOLVIMENTO } \\
\text { SÓCIO-AMBIENTAL }\end{array}$ & 2016 & $\begin{array}{l}\text { Doutorado } \\
\text { [PUR] }\end{array}$ & 4 \\
\hline
\end{tabular}

Fonte: elaborado a partir dos dados coletados no Relatório de Avaliação 2017 e da Plataforma Sucupira (acessado em maio de 2018).

Ao considerar o período de criação dos Cursos, a maior parcela foi criada após o ano de 1999, conforme se verifica na distribuição por período. (Gráfico 3)

Gráfico 3 Criação de Cursos na área PLURD (por nível) - 1970-2017.

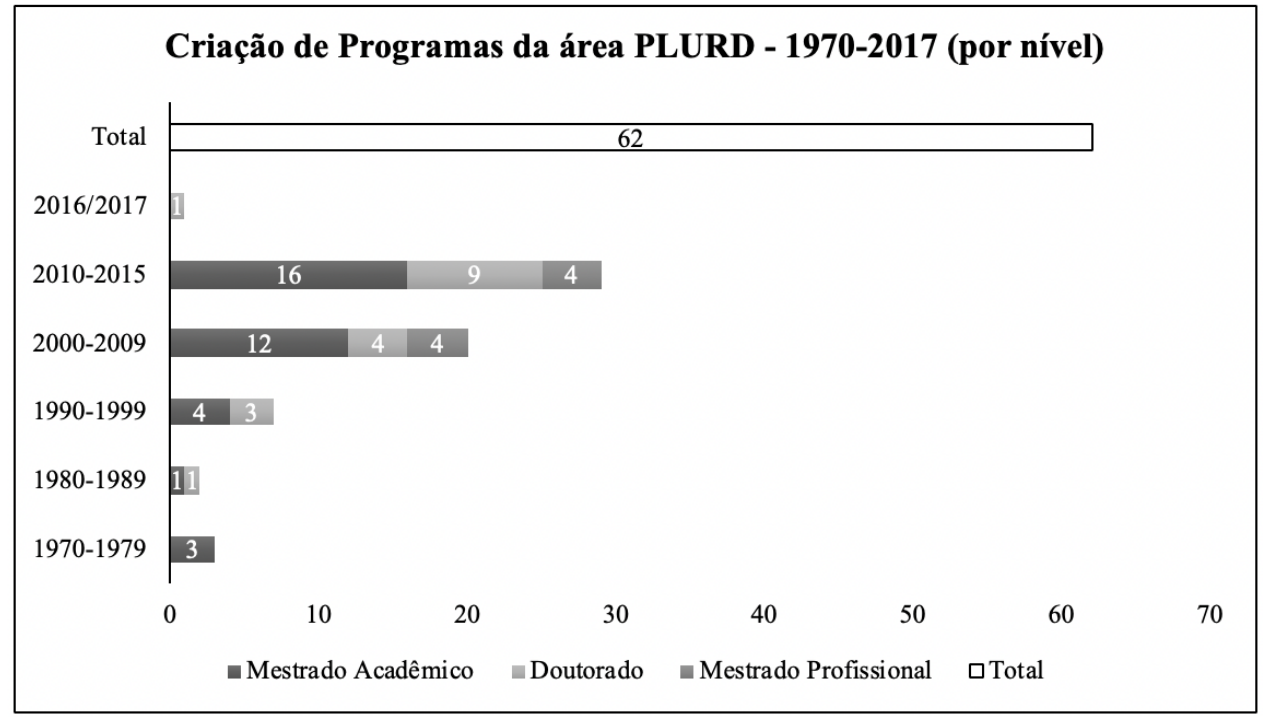

Fonte: elaborado com base nos dados da Plataforma Sucupira (maio/2018).

\footnotetext{
${ }^{8}$ É uma instituição comunitária, não possui dono e não visa o lucro, como as privadas, porém, há cobrança de mensalidades. Sendo assim, nesta análise, por não ser uma instituição municipal [não é mantida pela prefeitura exclusivamente] se optou em deixá-la, assim como está no relatório extraído da Plataforma Sucupira, junto das instituições de caráter jurídico particular.
} 
Ao considerar a nota/conceito destes, atualmente, a maior parte dos Programas estão com avaliação em nota 3 e 4 (Gráfico 4), destacando, a quantidade de apenas um Programa com nota 7, sendo este, o Programa em Demografia da Universidade Federal de Minas Gerais (UFMG). (Gráfico 4)

Gráfico 4 Notas e respectivo número de Programas na área PLURD (2010, 2013 e 2017).

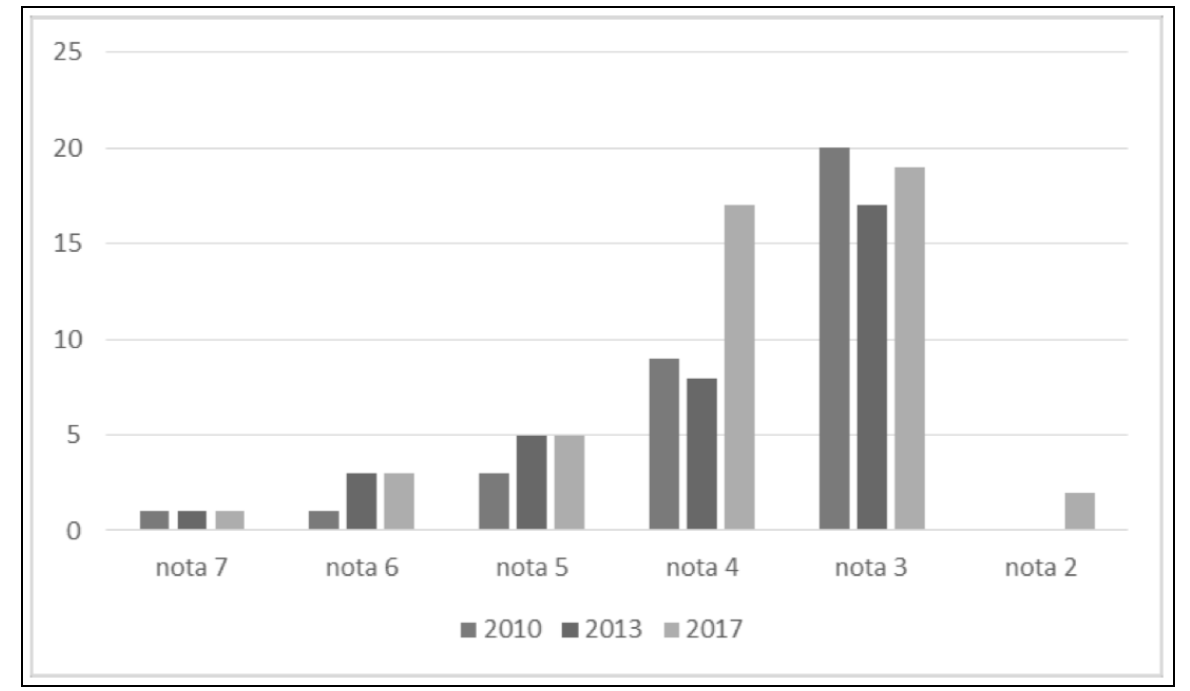

Fonte: extraído e adaptado do Relatório de Avaliação 2017.

Ao comparar o Relatório de Avaliação 2017 com o relatório de avaliação anterior revela que em 5\% dos Programas da área PLURD ocorreu diminuição da nota em 1 ponto; em 9\% houve aumento de 1 ponto na nota; e a maior parte dos Programas, 34\% deles, mantiveram suas notas anteriores, sobretudo, 3. Ainda, de acordo com o Relatório de Avaliação 2017 (p. 75), para os Programas com nota 6 [das instituições UFRJ / UNICAMP / UFRGS] e o Programa de Demografia, nota 7 [UFMG] ${ }^{9}$, “o que se espera [...] para o próximo período de avaliação, que já está em marcha, é o desenvolvimento de suas ações, alcançando um grau ainda maior de nucleação, solidariedade e internacionalização, conforme previsto no Documento de Área, principalmente considerando que esses Programas estão entre os mais antigos da Área PLURD”.

Com relação aos quesitos ${ }^{10}$ avaliados junto aos Programas, se pode destacar que dos Programas Profissionais, 55,6\% possuem a Proposta do Programa considerada "bom" e 33,3\% "muito boa". Corpo docente e produção intelectual foram os quesitos com menor

\footnotetext{
${ }^{9}$ Iniciou em 1985.

${ }^{10}$ Quesitos: 1) Proposta do Programa; 2) Corpo Docente; 3) Corpo Discente; 4) Produção Intelectual; 5) Inserção Social.
} 
percentual de avaliação "muito bom". Já, para os Programas Acadêmicos, fica claro que o quesito Produção Intelectual precisa avançar, sendo que em 7,9\% dos Programas é considerado "fraco". Em 50\% o quesito Proposta do Programa é considerado "bom", e em $36,8 \%$ "muito bom". Fato que chama a atenção ainda, diz respeito ao quesito corpo docente, pois, em 2,6\% dos Programas é considerado "deficiente". No quesito de inserção social, os Programas Acadêmicos foram avaliados de "regular" a "muito bom" e os Programas Profissionais de "fraco" a "muito bom". Desta forma, parece que os Programas Acadêmicos possuem uma melhor inserção social.

Como já exposto, são 46 Programas $^{11}$ da área PLURD, porém, se considerar para o cálculo, separando os cursos em Mestrado Profissional (MP), Mestrado Acadêmico (ME) e Doutorado (DO), chegamos a um número total de 62 cursos no Brasil (Gráfico 3), os quais, representam 1\% do total de Cursos de Pós-Graduação ofertados no país e aproximadamente 8\% dos Cursos ofertados na Grande Área das Ciências Sociais Aplicadas. Por sua vez, estão organizados da seguinte forma: (Figura 1)

Figura 1 Estrutura da distribuição dos Programas na área PLURD (2017).

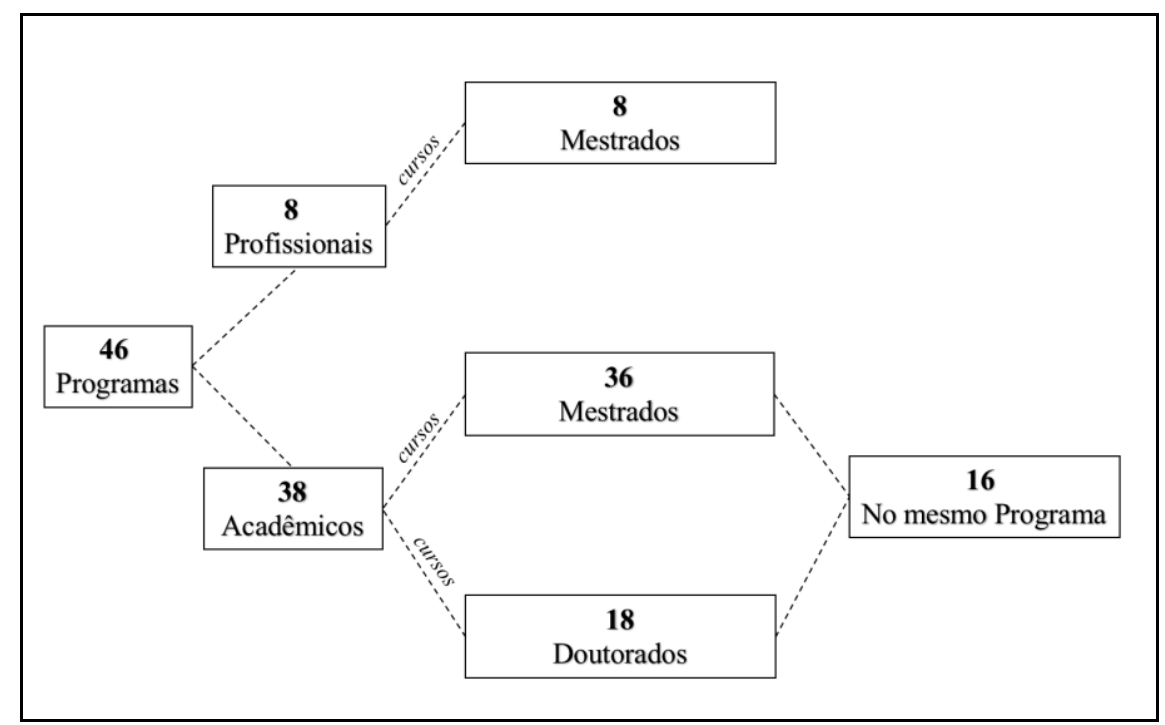

Fonte: elaborada a partir dos dados coletados no Relatório de Avaliação 2017 e da Plataforma Sucupira (acessado em maio de 2018).

Não se pode deixar de citar que dos 62 Cursos, $65 \%$ estão concentrados nas regiões Sudeste e Sul. A região Centro-Oeste foi a última a criar Programas na referida área, por meio da PUC de Goiás em 2006 e até atualmente, não possui nenhum doutorado. Destaque para o

\footnotetext{
${ }^{11}$ Muitos Programas possuem cursos de mestrado e doutorado (no mesmo Programa). 
fato de que nas regiões Norte e Centro-Oeste do Brasil, o primeiro mestrado foi criado 36 anos após o início do primeiro mestrado na área [PUR] no país (PORTO; THEIS, 2016).

Ao compreender que após 2006, se caracteriza uma fase dada pela "desconcentração regional e interiorização dos programas de pós-graduação de PUR no Brasil, mediante à criação dos primeiros cursos na área PUR nas regiões Norte e Centro-Oeste do Brasil" (PORTO; THEIS, 2016, p. 40), é importante destacar que em dez Unidades da Federação [Sudeste: Espírito Santo; Norte: Acre, Amazonas, Rondônia; Centro-Oeste: Distrito Federal, Mato Grosso; Nordeste: Alagoas, Ceará, Piauí, Sergipe] ainda não existem cursos na área PLURD, o que por sua vez, nos faz reflexionar que será preciso investir e canalizar esforços para que estes possam adentrar nas respectivas Unidades Federativas.

Ressalta-se que o Sul é a única região em que todos as Unidades Federativas possuem cursos na área ${ }^{12}$ e por outro lado, as regiões Nordeste e Norte são aquelas que possuem a maior quantidade de Unidades Federativas sem cursos na área analisada. E não raras vezes, em diversos eventos científicos da área, são justamente estas regiões em que há ausência de Programas na área, o foco de muitas discussões, como é o caso [a exemplo ${ }^{13}$ ] dos trabalhos publicados no XVII ENANPUR 2017: i) “A política de regularização fundiária urbana de interesse social: algumas conclusões a partir da pesquisa nas regiões Norte e Nordeste" (FISCHER; SIQUEIRA, 2017, p. 35); ii) "Planejamento regional no Nordeste: a (re)produção de um processo arcaico" (CASTRO; CARDOSO; SOUSA, 2017, p. 69).

De acordo com dados da Plataforma Sucupira e GeoCapes, a área PLURD é uma das que menos apresenta docentes permanentes, aqueles efetivos, (em média) comparativamente com as outras áreas de avaliação da Capes dos últimos quatro anos. Do total de docentes da área, $80 \%$ são considerados "permanentes". Ademais, em média, o tempo para a titulação de Mestrado está compreendido entre 25 e 30 meses e de Doutorado entre 50 e 55 meses. Considerando o número de teses defendidas, a área PLURD figura entre as últimas posições, com menos de 1000 teses defendidas até dezembro de 2016. Os Programas mais recentes (após 2010) em sua maior parte, foram criados por instituições de status jurídico federal e privado. E sobre este quesito de análise, de forma geral, a maior parte dos Programas estão

\footnotetext{
${ }^{12}$ Inclusive, um dos últimos Programas (Doutorado Acadêmico) foi criado em Santa Catarina, no ano de 2016. É o Programa de Pós-Graduação em Planejamento Territorial e Desenvolvimento Socioambiental (PPGPLAN) da Universidade do Estado de Santa Catarina (UDESC).

${ }^{13}$ Diversos outros trabalhos poderiam ser citados, de diferentes fontes, inclusive. Porém, o intuito do presente texto não é perfazer esta análise.
} 
sendo oferecidos por instituições privadas e federais ( $76 \%$ do total, conforme se verifica). (Tabela 1)

Tabela 1 Programas da área PLURD Capes, distribuídas por status jurídico.

\begin{tabular}{l|c|c|c|c|c}
\hline REGIÕES & FEDERAL & PRIVADA & ESTADUAL & MUNICIPAL & TOTAL \\
\hline CENTRO-OESTE & 0 & 2 & 1 & 0 & $\mathbf{3}$ \\
\hline NORTE & 4 & 1 & 0 & 0 & $\mathbf{5}$ \\
\hline NORDESTE & 3 & 3 & 3 & 0 & $\mathbf{9}$ \\
\hline SUDESTE & 7 & 5 & 1 & 1 & $\mathbf{1 4}$ \\
\hline SUL & 5 & 5 & 3 & 2 & $\mathbf{1 5}$ \\
\hline TOTAL & $\mathbf{1 9}$ & $\mathbf{1 6}$ & $\mathbf{8}$ & $\mathbf{3}$ & $\mathbf{4 6}$ \\
\hline $\mathbf{\%}$ & $\mathbf{4 0}$ & $\mathbf{3 5}$ & $\mathbf{1 7}$ & $\mathbf{6}$ & $\mathbf{1 0 0}$ \\
\hline
\end{tabular}

Fonte: elaborada com base nos dados da Plataforma Sucupira (maio/2018).

A região Sudeste é aquela que mais possui programas na área de avaliação PLURD ofertados por instituições federais. Por outro lado, as regiões Sul e Sudeste são aquelas que apresentam oferta de Programas em instituições com status jurídico municipal. Ao considerar o panorama acerca das notas dos Programas, se buscou e tabulou-se todos os Programas da área de avaliação PLURD da Capes, suas respectivas notas e região, onde se encontram, verificando desta forma, que a região Sul, em média simples, é aquela em que apresenta as melhores notas dos seus Programas na área de avaliação PLURD Capes, seguida da região Sudeste. Por outro lado, de acordo com os dados compilados, a região Centro-Oeste é a que apresenta a menor média simples de notas dos Programas na área avaliada. (Tabela 2)

Tabela 2 Notas dos Cursos da área PLURD Capes, distribuídas por região.

\begin{tabular}{l|c|c|c|c|c|c|c|c}
\hline \multirow{2}{*}{ Regiões } & \multicolumn{5}{|c|}{$\begin{array}{c}\text { Notas do Cursos } \\
\text { Acadêmicos }\end{array}$} & \multicolumn{2}{c}{$\begin{array}{c}\text { Notas dos } \\
\text { Cursos } \\
\text { Profissionais }\end{array}$} & \multirow{2}{*}{$\begin{array}{c}\text { Total de } \\
\text { Cursos }\end{array}$} \\
\cline { 2 - 8 } & 3 & 4 & 5 & 6 & 7 & 3 & 4 & \\
\hline $\begin{array}{l}\text { Centro- } \\
\text { Oeste }\end{array}$ & 2 & - & - & - & - & 1 & - & $\mathbf{3}$ \\
\hline Norte & 3 & 2 & - & - & - & 1 & - & $\mathbf{6}$ \\
\hline Nordeste & 5 & 4 & 2 & - & - & 1 & - & $\mathbf{1 2}$ \\
\hline Sudeste & 5 & 7 & - & 4 & 2 & 1 & 1 & $\mathbf{2 0}$ \\
\hline Sul & 5 & 3 & 8 & 2 & - & 2 & 1 & $\mathbf{2 1}$ \\
\hline Total & $\mathbf{2 0}$ & $\mathbf{1 6}$ & $\mathbf{1 0}$ & $\mathbf{6}$ & $\mathbf{2}$ & $\mathbf{6}$ & $\mathbf{2}$ & $\mathbf{6 2}$ \\
\hline
\end{tabular}

Fonte: elaborada com base nos dados da Plataforma Sucupira (maio/2018).

Pormenorizando os dados, se verifica que dentre os Cursos acadêmicos e profissionais, predominam as notas 3 e 4 . Ao considerar os Cursos profissionais, em menor parcela do total - 13\%, apenas dois dos oito possuem nota 4 (Planejamento Regional e Gestão da Cidade - 
UCAM/RJ e Planejamento Territorial e Desenvolvimento Socioambiental - UDESC/SC). Os demais estão todos avaliados com nota 3. Quanto aos Programas Acadêmicos [do total de 46, estes somam 38], 63\% estão, concentrados nas regiões Sul e Sudeste. As instituições de status jurídico federal e privado são aquelas em que mais ofertam Programas Acadêmicos na área PLURD. (Quadro 3)

Quadro 3 Distribuição de notas [Programas Acadêmicos], por status jurídico e região do país (maio/2018).

\begin{tabular}{|c|c|c|c|c|c|c|c|c|c|c|c|c|c|c|c|}
\hline \multirow{3}{*}{ Região } & \multicolumn{15}{|c|}{ Notas } \\
\hline & \multicolumn{3}{|c|}{ Privada } & \multicolumn{5}{|c|}{ Federal } & \multicolumn{4}{|c|}{ Estadual } & \multicolumn{2}{|c|}{ Municipal } & \multirow[t]{2}{*}{ Total } \\
\hline & 3 & 4 & 5 & 3 & 4 & 5 & 6 & 7 & 3 & 4 & 5 & 6 & 3 & 5 & \\
\hline Centro-Oeste & 1 & - & - & - & - & - & - & - & 1 & - & - & - & - & - & 2 \\
\hline Norte & - & 1 & - & 2 & 1 & - & - & - & - & - & - & - & - & - & 4 \\
\hline Nordeste & 1 & 1 & - & - & 2 & 1 & - & - & 3 & - & - & - & - & - & 8 \\
\hline Sudeste & 1 & 2 & - & 3 & 2 & - & 1 & 1 & - & - & - & 1 & 1 & - & 12 \\
\hline Sul & 1 & 1 & 2 & 3 & - & - & 1 & - & - & 1 & 1 & - & 1 & 1 & 12 \\
\hline Total & 4 & 5 & 2 & 8 & 5 & 1 & 2 & 1 & 4 & 1 & 1 & 1 & 2 & 1 & 38 \\
\hline
\end{tabular}

Fonte: elaborado a partir dos dados coletados na Plataforma Sucupira (maio/2018).

Sobre os Programas Profissionais, em nenhuma instituição de status jurídico municipal estes são ofertados, apenas por instituições $\operatorname{privadas}^{14}$, federais e estaduais, sendo que aqueles ofertados por privadas representa $50 \%$ do total (Quadro 4). Aqui, vale uma contribuição reflexiva de Piquet; Vilani (2013), quando expõem que os Programas de Pós-Graduação profissionais representam uma importância muito significativa para o processo de formação profissional, dando condições para que seja possível se realizar leituras adequadas e propor medidas positivas à construção de uma sociedade mais justa e igualitária, deve-se considerar os termos sustentáveis. Porém, estes, na área de avaliação PLURD, representam a menor parcela. E mais, conforme aponta o Relatório de Avaliação 2017, há uma tendência de diminuição dos alunos matriculados neste nível de formação. (Quadro 4)

Quadro 4 Distribuição de notas [Cursos Profissionais], por status jurídico e região do país (maio/2018).

\begin{tabular}{|l|c|c|c|c|c|}
\hline \multirow{2}{*}{ Região } & \multicolumn{5}{c|}{ Notas } \\
\cline { 2 - 5 } & \multicolumn{2}{|c|}{ Privada } & Federal & Estadual & \multirow{2}{*}{ Total } \\
\cline { 2 - 5 } & 3 & 4 & 3 & 4 & $\mathbf{1}$ \\
\hline Centro-Oeste & 1 & - & - & - & $\mathbf{1}$ \\
\hline Norte & - & - & 1 & - & $\mathbf{1}$ \\
\hline Nordeste & 1 & - & - & - & $\mathbf{2}$ \\
\hline Sudeste & 1 & 1 & - & - & $\mathbf{3}$ \\
\hline Sul & 1 & - & 1 & 1 & $\mathbf{8}$ \\
\hline Total & $\mathbf{4}$ & $\mathbf{1}$ & $\mathbf{2}$ & $\mathbf{1}$ & \\
\hline
\end{tabular}

Fonte: elaborado a partir dos dados coletados na Plataforma Sucupira (maio/2018).

${ }^{14}$ Lembrando, a UNOCHAPECÓ é uma instituição “comunitária”, porém, para a análise aqui proposta, se optou
em agrupá-la àquelas de status jurídico privado, conforme também, dados da Plataforma Sucupira. 
As regiões Sul e Sudeste apresentam maior oferta de Programas na área de avaliação PLURD, Acadêmicos e Profissionais, se destacam nos primeiros. Porém, ainda é baixo o número de Programas com notas superiores a 6, tanto, Acadêmicos, quanto, Profissionais.

Cabe mencionar que o processo de expansão dos Programas na área PLURD, é também, resultado do estímulo da Associação Nacional de Pós-graduação e Pesquisa em Planejamento Urbano e Regional (ANPUR), uma entidade jurídica de direito privado, sem fins lucrativos, que congrega programas universitários de pós-graduação e entidades brasileiras que desenvolvem atividades de ensino e/ou pesquisa no campo dos estudos urbanos e regionais e do planejamento urbano e regional. É uma associação pluridisciplinar e aberta, cujas finalidades principais abrangem: o incentivo ao estudo, ao ensino e à pesquisa nesse campo do conhecimento; a divulgação de informações e a troca de experiências referentes a essas áreas de atuação; a promoção de reuniões científicas objetiva o intercâmbio de informações entre os integrantes das instituições associadas e, também, com outras associações congêneres, nacionais e estrangeiras (ANPUR, 2018).

Fundada em 1983, a ANPUR, desde então ampliou significativamente o número e o espectro de instituições associadas e filiadas, e reúne hoje cinquenta e sete membros, atuantes nas áreas do planejamento urbano e regional, do desenvolvimento regional, da arquitetura e urbanismo, da geografia, da economia, da administração pública, das ciências sociais e outras. São realizados Encontros Nacionais a cada dois anos (ENANPUR), dos quais são regularmente publicados os Anais. Realizado este panorama, e objetivando uma síntese, com maior representatividade ao visual, até então não encontrado em materiais publicados, se elaborou a presente representação ${ }^{15}$ (Figura 2), cujo objetivo está em demonstrar as regiões em que são ofertados os Programas, por meio dos seus Cursos, da área PLURD da Capes. (Figura 2)

O que mais evidencia-se é a "lacuna" no território brasileiro [região Norte e CentroOeste, sobremaneira] na oferta de Programas na área de avaliação PLURD. Ademais, a região Nordeste, também se encontra relativamente desassistida por Programas na área, considerando que em cinco Unidades Federativas não há a presença de mestrados e doutorados.

Salienta-se que, por ser uma área que busca a interdisciplinaridade, é fundamental que todas as regiões do país estejam com anseios de instalação destes Programas, e aquelas que já

\footnotetext{
${ }^{15}$ Sem o intuito de levar em consideração as escalas geográficas, apenas como forma representativa e visual. 
os possuem, que lutem para permanecerem com eles, buscando suas qualificações, entendendo que são fundamentais ao processo de desenvolvimento regional, urbano e nacional. Sobre a qualificação, fator muito relevante para avaliar a "qualidade" dos Programas diz respeito as suas publicações em periódico [produção intelectual, que representa $50 \%$ do peso total do quesito de avaliação "produção intelectual"]. Desta forma, considerando a avaliação dos periódicos, por estrato de avaliação na área, se pode verificar que os maiores números de publicações estão nos estratos "B5” (26,7\%) e "B4” (21,5\%): (Gráfico 4)

Figura 2 Representação da distribuição territorial dos Programas da área PLURD (2017).

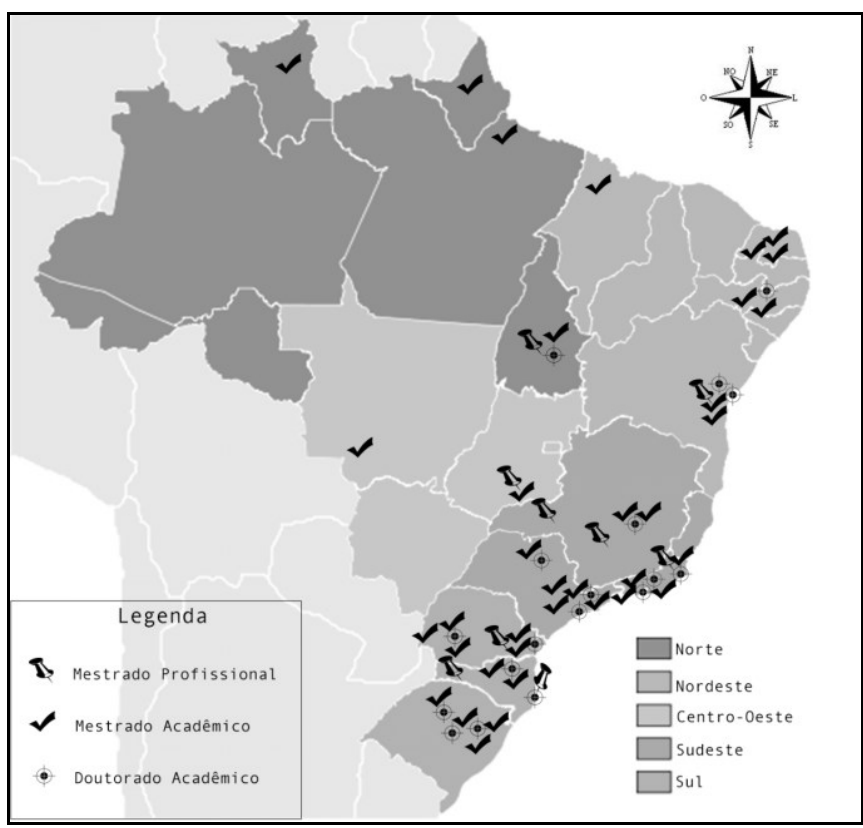

Fonte: elaborada a partir dos dados coletados no Relatório de Avaliação 2017 e da Plataforma Sucupira (maio/2018).

Gráfico 4 Estratos das publicações [em periódicos] dos Programas na área PLURD.

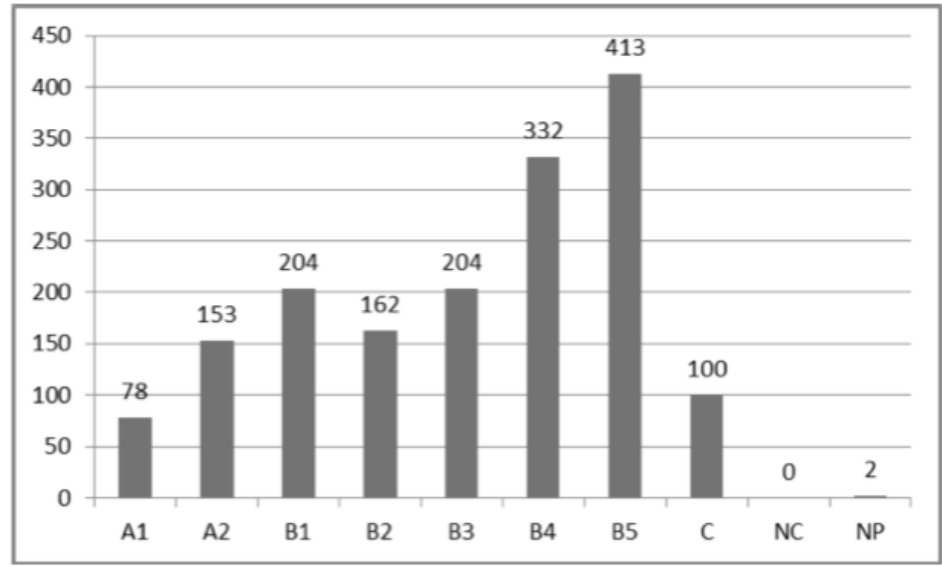

Fonte: extraído e adaptado do Relatório de Avaliação 2017. 
Ao considerar o número de artigos publicados [por docente permanente], a área PLURD está na posição de número $32^{\circ}$ dentre as 49 avaliadas, sendo que é baixo o número de publicações, comparativamente às outras áreas, em periódicos com qualis A1 e A2. Desta forma, é preciso avançar com as publicações [artigos] em periódicos com melhores qualificações, A1 e A2, respectivamente. Por outro lado, o total de livros e capítulos [por docente permanente] é significativo, tanto que a área, neste quesito, está na posição de número $14^{\circ}$ dentre as 49 avaliadas. O Relatório de Avaliação 2017 ainda revelou um dado muito interessante: os docentes e discentes dos Programas da Área de Planejamento Urbano e Regional e Demografia (PLURD) publicaram em 1.648 periódicos entre 2013 a 2016.

A este respeito, de acordo com a Plataforma Sucupira (maio/2018), estão classificados na área PLURD 1.902 periódicos ${ }^{16}$, sendo que a maior parte deles estão nos estratos "B5" e “B4”. (Gráfico 5)

Gráfico 5 Classificações dos periódicos avaliados para área PLURD.

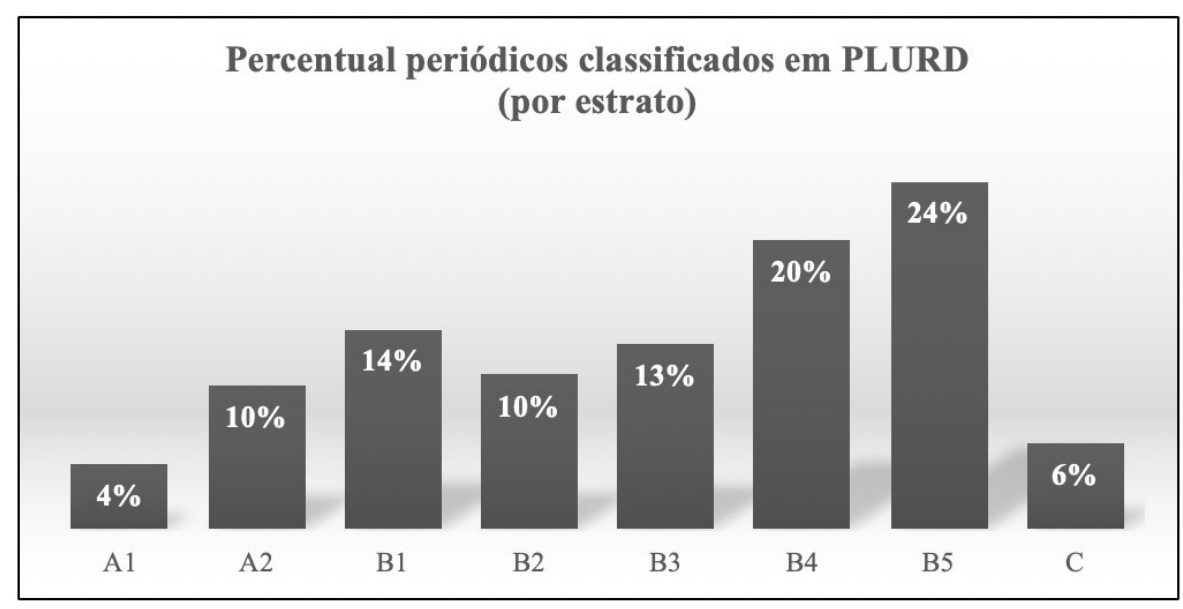

Fonte: elaborado com base nos dados da Plataforma Sucupira (maio/2018).

Sobre as temáticas abordadas pelos pesquisadores da área, Piquet; Ribeiro (2008) destacaram que na década de 1950 e início de 1960 os temas eram voltados ao planejamento para a mudança e relevância da questão do desenvolvimento; na década de 1970 e início de 1980, voltados para a discussão do planejamento tecnocrático [tema que atualmente é utilizado como contraponto de críticas, como por exemplo, fazem Pereira $(2015$; 2017) e Maricato (2009)] e controle da escala nacional; nas décadas de 1980 e 1990, predominavam os temas de gestão e centralidade atribuídas às forças de mercado; nos anos 2000, se

${ }^{16}$ A Revista Brasileira de Estudos Urbanos e Regionais (RBEUR) é, no âmbito da ANPUR, como aponta Limonad (2017), um dos principais meios para dar a necessária e objetivada visibilidade à Associação e à área. 
retomaram as discussões sobre a questão do desenvolvimento e crescente preocupação com o planejamento de longo prazo, como por exemplo, por meio da aplicabilidade dos dispositivos do Estatuto da Cidade (Lei 10.257/2001). Ao figurar, esta última temática, muito presente, e necessária, ao processo de planejamento territorial.

\section{NOTAS FINAIS}

Diante da exposição dos motivos elencados, sobre o panorama dos Programas de PósGraduação em PLURD, se constata o aumento do número de Programas de Pós-Graduação na área de Planejamento Urbano e Regional e Demografia da Capes nas últimas duas décadas, porém, ainda há uma lacuna, sobretudo, nas regiões Norte e Centro-Oeste, seguidas da região Nordeste. Considerando o que expõem Piquet; Vilani (2013) que a capacitação profissional é requisito básico para a entrada no mercado de trabalho, bem como, para contribuir com o "progresso" do país [inclusive social e econômico], pouco se tem estimulado para a criação dos Programas Profissionais, sobretudo, Mestrados [estes são apenas oito], tendo em vista que é recente a autorização e reconhecimento no país de Doutorado nesta modalidade.

No que diz respeito aos Doutorados, se expõe a ausência de Programas na área PLURD na região Centro-Oeste. Já, na região Norte, há apenas um Programa de Doutorado na Unidade Federativa do Tocantins. Posto isso, refuta-se o que dizem Porto; Theis (2016, p. 43) quando afirmam que cursos de Mestrados Acadêmicos e Mestrados Profissionais, bem como Doutorados, "atingiram todas as regiões brasileiras, formando massa crítica sobre as questões regionais e urbanas". Como se observou na Figura 2, ainda existe muita concentração dos Programas e desta forma, a massa crítica desta área ainda carece ampliar a oferta pelo território brasileiro.

O único Programa com nota 7 na área de avaliação PLURD da Capes no Relatório de Avaliação 2017 é o Programa em Demografia da Universidade Federal de Minas Gerais (UFMG), criado em 1985. Assim sendo, não necessariamente o tempo de instalação de um Programa é fator primordial para elevada nota, mas sim, as ações desenvolvidas no âmbito de sua gestão da infraestrutura física e intelectual, frisando ainda, a integração do corpo docente. Ao analisar dados acerca da criação dos Programas na área PLURD da Capes ao longo das mais de quatro décadas, desde os seus primeiros na UFRGS (1970), UFRJ (1972) e UFPE (1975), se nota que nas regiões e seus entornos [mesma região geográfica, considerando a 
divisão regional do adotada pelo IBGE] e em períodos subsequentes, novos Programas surgiram. Seria uma coincidência? Difícil.

Por fim, cabe dizer que, sendo as instituições de ensino, por meio de sua estrutura intelectual e física, as grandes canalizadoras do pensamento e da ação reflexiva, é fator fundamental novos Programas, como se espera, em regiões que até então estão “desassistidas", sendo que a área de PLURD, a partir de suas contribuições em temáticas multi, inter e transdisciplinares ${ }^{17}$, tem muito a oferecer para o processo de positivo desenvolvimento: no escopo de análise [teórica e aplicações práticas, no caso dos MP] local, regional e nacional.

\section{REFERÊNCIAS}

ANPUR. Associação Nacional de Pós-graduação e Pesquisa em Planejamento Urbano e Regional (ANPUR). Disponível em: $<$ http://anpur.org.br/sobre-a-anpur/> Acessado em: abr. de 2018.

CAPES. Relatório de Avaliação do Quadriênio 2017 (2013-2016). Disponível em:< http://capes.gov.br/images/documentos/Relatorios quadrienal 2017/RELATORIO AVALIA CAO_QUADRIENAL_2017 FINAL_reunido.pdf> Acessado em: maio de 2018.

CASTRO, D. M. De.; CARDOSO, G. N.; SOUSA, L. G. De. Planejamento regional no Nordeste: a (re)produção de um processo arcaico. In: ENANPUR - Encontro Nacional da Associação Nacional de Pós-Graduação e Pesquisa em Planejamento Urbano e Regional (XVII.: 2017: São Paulo, SP) Caderno de Resumos - XVII Encontro Nacional da Associação Nacional de Pós-Graduação e Pesquisa em Planejamento Urbano e Regional / Organizadores: Eduardo Nobre, Camila D’Ottaviano. - São Paulo: Faculdade de Arquitetura e Urbanismo da Universidade de São Paulo, 2017. p. 69.

CGEE - Centro de Gestão e Estudos Estratégicos. Doutores 2010: estudos da demografia da base técnico-científica brasileira - Brasília, DF: Centro de Gestão e Estudos Estratégicos, 2010. Disponível em: http://www.cgee.org.br/publicacoes/mestres e dou tores.php. Acessado em: maio 2018.

ENANPUR - Encontro Nacional da Associação Nacional de Pós-Graduação e Pesquisa em Planejamento Urbano e Regional (XVII.: 2017: São Paulo, SP) Caderno de Resumos - XVII Encontro Nacional da Associação Nacional de Pós-Graduação e Pesquisa em Planejamento Urbano e Regional / Organizadores: Eduardo Nobre, Camila D’Ottaviano. São Paulo: Faculdade de Arquitetura e Urbanismo da Universidade de São Paulo, 2017.

FISCHER, L. R. Da C.; SIQUEIRA, L. De A. A política de regularização fundiária urbana de interesse social: algumas conclusões a partir da pesquisa nas regiões Norte e Nordeste. In: ENANPUR - Encontro Nacional da Associação Nacional de Pós-Graduação e Pesquisa em

\footnotetext{
${ }^{17}$ Muitas das quais podem ser consultadas na Revista Brasileira de Estudos Urbanos e Regionais (RBEUR), disponível em: $<$ http://rbeur.anpur.org.br/rbeur/index $>$, avaliada pela Capes com estrato A2.
} 
Planejamento Urbano e Regional (XVII.: 2017: São Paulo, SP) Caderno de Resumos - XVII Encontro Nacional da Associação Nacional de Pós-Graduação e Pesquisa em Planejamento Urbano e Regional / Organizadores: Eduardo Nobre, Camila D'Ottaviano. São Paulo: Faculdade de Arquitetura e Urbanismo da Universidade de São Paulo, 2017. p. 35.

LIMONAD, E. Lá se vão trinta anos de ANPUR....Revista Brasileira de Estudos Urbanos e Regionais, [S.1.], v. 19, n. 2, p. 219, abr. 2017. ISSN 2317-1529. Disponível em: $<$ http://rbeur.anpur.org.br/rbeur/article/view/5567/4783>. Acessado em: jun. de 2018.

MARICATO, E. O lugar fora das ideias e as ideias fora do lugar. In: ARANTES, O.; VAINAR, C.; MARICATO, E. A cidade do pensamento único. Desmanchando consensos. Petrópolis, RJ: Vozes, 2009.

PEREIRA, E. M. Alegoria da Participação: planos diretores participativos pós-estatuto da cidade. Florianópolis: Insular, 2015.

PEREIRA, E. M. Como anda a participação? As condições para a elaboração de Planos Diretores Participativos. Rev. Bras. Estud. Urbanos Reg., RECIFE, V.19, N.2, p.235-250, MAIO-AGO. 2017.

PIQUET, R. P. da S.; RIBEIRO, A. C. T. Tempos, idéias e lugares: o ensino do Planejamento Urbano e Regional no Brasil. Revista Brasileira de Estudos Urbanos e Regionais, [S.1.], v. 10, n. 1, p. 49, maio 2008. ISSN 2317-1529. Disponível em:

$<$ http://rbeur.anpur.org.br/rbeur/article/view/191>. Acessado em: maio de 2018.

PIQUET, R.; VILANI, R. M. O papel dos mestrados profissionais na área de Planejamento Urbano e Regional. Revista Brasileira de Estudos Urbanos e Regionais, [S.1.], v. 15, n. 1, p. 95, maio 2013. ISSN 2317-1529. Disponível em:

$<$ http://rbeur.anpur.org.br/rbeur/article/view/4172>. Acessado em: jun. de 2018.

PORTO, J. L. R.; THEIS, I. M. A Pós-Graduação em Planejamento Urbano e Regional no Brasil: quatro décadas de reflexões territoriais. PRACS: Revista Eletrônica de Humanidades do Curso de Ciências Sociais da UNIFAP, v. 9, p. 33-46, 2016.

RANDOLPH, R. Em busca de uma agenda para o Planejamento Urbano e Regional: uma homenagem a Ana Clara Torres Ribeiro. Revista Brasileira de Estudos Urbanos e Regionais, [S.1.], v. 15, n. 1, p. 11, maio 2013. ISSN 2317-1529. Disponível em: $<$ http://rbeur.anpur.org.br/rbeur/article/view/4168>. Acessado em: jun. de 2018.

\section{Sites acessados}

-ANPUR: http://www.anpur.org.br

-CAPES: www.capes.gov.br/avaliacao/avaliacao-da-pos-graduacao

-PLATAFORMA SUCUPIRA: www.sucupira.capes.gov.br 